
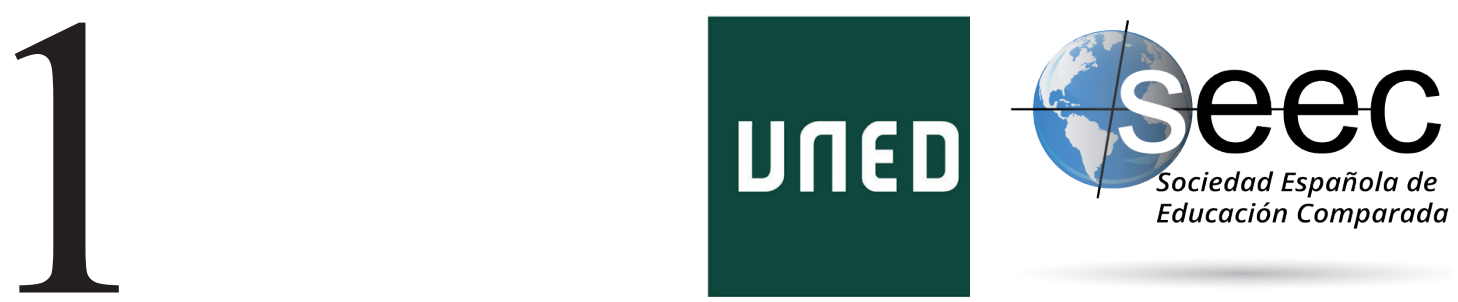

\title{
Editorial: Educación y Refugiados
}

Editorial: Education and Refugees

\section{Agustín Velloso de Santisteban*}

DOI: $10.5944 /$ reec.35.2020.26170

Recibido: 20 de julio de 2019 Aceptado: 2 de diciembre de 2019

\footnotetext{
* Agustín Velloso de Santisteban: es profesor de Educación Comparada y Educación y Desarrollo: problemas del Tercer Mundo en la Universidad Nacional de Educación a Distancia. Investiga y publica principalmente sobre educación de refugiados, educación y política en Iraq, Palestina y el Sahara Occidental, así como sobre Guinea Ecuatorial. Datos de contacto: E-mail: avelloso@edu.uned.es
} 
No es descabellado decir que hoy día no hay nadie que no tenga alguna idea sobre la situación de los refugiados en el mundo. Desde luego que esto no significa que todas las personas conozcan las causas, los responsables, las medidas tomadas por los gobiernos, menos aún lo que dice la ley internacional, tampoco la solución a este fenómeno mundial.

Más bien se puede decir que la confusión es lo que prevalece, en gran parte de forma intencionada y debida a intereses políticos.

A través de los medios de comunicación se promueve una serie de ideas descabelladas formuladas por gobernantes y otros políticos en ejercicio, líderes sociales y de opinión sobre un supuesto «asalto por parte de refugiados e inmigrantes», sobre «invasiones» de extranjeros que se trasladan a países occidentales para imponerse demográfica, cultural y religiosamente a los nativos; las autoridades concernidas implantan medidas de «seguridad» principalmente de carácter militar desde antes de la llegada y otras represivas durante la recepción y la estancia, desde luego ilegales o ilegítimas como la expulsión, la no asistencia a los náufragos, la detención y otras igualmente contrarias a los derechos humanos básicos y la propia dignidad humana.

En medio de la ignorancia, la manipulación y la confusión, también de las violaciones de la ley internacional, las ciencias sociales tienen la responsabilidad de ocuparse de este asunto con toda su capacidad y potencia para explicar el fenómeno del refugio, predecir su evolución y contribuir a la formulación de las políticas y acciones más convenientes y siempre acordes con los derechos humanos y la ley internacional.

Este número monográfico ha reunido estudios sobre algunos temas de interés, tanto educativos como sociales y políticos, desde diversas especialidades y también desde varios continentes y regiones: Oriente Medio, Norte de África, Europa y América.

Ramzy Baroud y Romana Rubeo se ocupan de un asunto muy notorio en la actualidad, cuyo desenlace aún por producirse puede culminar la obra de desposesión de Palestina iniciada en el siglo pasado. En esta ocasión Estados Unidos la presenta con una fórmula rocambolesca: «el acuerdo del siglo».

Sólo conociendo la historia de un siglo de apropiación de la tierra y la expulsión de su población se puede entender el sistema educativo palestino, ya que se desarrolla bajo la ocupación militar de Israel desde el año 1967.

José Antonio Vinagrero, conocedor in situ de la vida en los campamentos de refugiados saharauis en Argelia, se ocupa de una cuestión que -aunque bastante desconocida para las generaciones más jóvenes- puede considerarse todavía una herida abierta para las anteriores que vivieron la pésima descolonización española del territorio del Sahara Occidental, que además es hoy literalmente sangrante para los saharauis de todas las edades.

Los logros del sistema educativo levantado por la población saharaui refugiada en el desierto constituyen el objeto de estudio del autor, quien también aborda la actuación de España a lo largo de los años, así como su labor humanitaria con los refugiados.

Oscar Navarro, por su parte, completa el estudio anterior centrando el suyo en la educación especial y añadiendo una comparación entre el Sahara y España. Para ello se ocupa minuciosamente de dos centros de educación especial, uno en Tinduf (Argelia) y otro en Ciudad Real (España). En este caso procede además a la comparación entre los dos centros educativos, con lo que deja patente la relación entre el contexto de cada centro y la organización, medios, problemas y demás características de ambos.

El trabajo de Julia Rubio, María José Vico y María Ángeles Pascual es también un estudio de caso sobre la educación compensatoria, aunque diferente del anterior porque 
es longitudinal. En sus palabras: «Se trata de hacer un análisis inferencial a partir de los porcentajes de los datos recogidos en seis cursos académicos consecutivos en tres modalidades determinadas de programas de educación compensatoria».

Tras diseccionar lo que significa esta educación, sus objetivos, planteamientos, legislación y administración, aborda tres modelos de enseñanza compensatoria que se emplean con el alumnado de un instituto de enseñanza secundaria público. Los refugiados comparten con inmigrantes y también con alumnado local, las actuaciones del cuerpo de profesores. La autora deja patente en sus conclusiones las carencias de los modelos empleados. Inevitablemente esto lleva a una reflexión que sale del aula para interpelar directamente al deterioro económico en España, lo que lamentablemente se conoce con el eufemismo de crisis.

Julia Castro ahonda también en otra crisis, la de Brasil. Su objetivo son los emigrantes, principalmente económicos, que acuden en busca de trabajo a este país. Esta población en marcha no se da en exclusiva en este país, se da en muchos otros. Lo más interesante del estudio de Castro es la combinación de la aportación de los estudios coloniales (es decir, críticos con el colonialismo) por un lado y de los estudios políticos y jurídicos sobre los «refugiados económicos» por otro.

Se puede decir, pues, que se realiza una doble crítica en el estudio. Aunque la colonial cuenta con una historia de dos décadas, el empleo del término «refugiado económico» es más reciente y, en realidad, es un engaño urdido por sus promotores. En definitiva, hace los mismos años que se sabe que «el refugiado económico de hoy es el refugiado político de mañana». Por ello este artículo demuestra certeramente la importancia no solo de las definiciones, sino de analizar críticamente cada situación de los distintos movimientos de población. A fin de cuentas lo más importante es ser consciente de que nos referimos a víctimas de violaciones de derechos humanos, políticos, sociales, económicos, culturales en todo lugar y tiempo.

No por casualidad Guillermo Castillo apunta en una dirección similar, aunque en esta ocasión se ocupa de los migrantes latinoamericanos en dirección hacia Estados Unidos. Como el estudio anterior, este muestra su potencia explicativa sobre la realidad del emigrante -y las realidades circundantes: miseria, violencia, represión, estigmatización, violaciones y un largo etc.- analizando concienzudamente conceptos que se usan de forma descuidada, aunque más bien hay que señalar que de forma intencionada por los que tienen intereses espurios.

Como sucede en Europa, también en otros continentes, en Norteamérica se trata mal de palabra y de obra al emigrante y como mucho se menciona entre las razones de la emigración las relativas a las violaciones de derechos humanos en los países de salida, pero nunca las violaciones de esos mismos derechos (junto con violencia de todo tipo y grado, desde guerras económicas, bloqueos y hasta la guerra de agresión) por parte de los países de llegada. Con otras palabras: estos callan aquellas violaciones en el mejor de los casos y son cómplices de los gobiernos que las cometen en la mayoría de los casos.

Icíar Villacieros concentra su estudio en el estrés sufrido por emigrantes adolecentes en Arica y Antofagasta, dos ciudades cuya economía está dedicada principalmente a la minería intensiva, aunque la segunda dobla a la primera en muchos aspectos: población y potencia económica en particular.

Es en esta actividad económica en la que como mano de obra van a trabajar emigrantes de Bolivia, Perú y Colombia. 
Tras analizar el contexto migratorio en Latinoamérica, la autora se sitúa en el chileno y pasa inmediatamente al estrés por aculturación. Su estudio se basa en analizar el papel de las familias emigrantes sobre la salud psicológica de sus hijos adolescentes y su relación con el estrés propio de la emigración.

Sus resultados confirman la hipótesis planteada, aunque la autora tiene la valentía y honradez de señalar también lo que considera «limitaciones del estudio». Por mi parte, desde luego, sus conclusiones no se ven afectadas por estas, pues las confirma sin reservas el sentido común y el conocimiento del ser humano en circunstancias agresivas.

Las autoras María del Pilar Quicios, Ana Huesca y Patricia González Ocejo se ocupan también de la cuestión que trata Villacieros. El término que emplean no es únicamente el de esta - «estrés por aculturación»- sino que presentan otros, de la medicina, en concreto de la psiquiatría: «una enfermedad emocional», «un desajuste psicosocial», también el de «estrés por choque cultural».

Lo que más interesa es que desmenuzan los síntomas de lo que consideran -con toda razón- «los cuatro dramas de los desplazados». Los dos primeros consisten en las dificultades para trabajar con el fin de mantenerse y mantener a la familia que se queda en el país de origen; los otros dos en las dificultades para vivir con las durísimas circunstancias que atraviesan en el país de destino y comunicárselas a sus seres queridos.

El siguiente paso es acudir al papel que la educación puede realizar para aligerar esos dramas. No deseo exagerar, pero una vez más la educación, en concreto la Educación Social, es la 'política de último recurso' que usan los gobiernos para arreglar el estropicio que causan con el resto de sus políticas a la población (de su país y sobre todo de otros).

El estudio de Adrián Neubauer se ocupa del derecho a la educación que tienen los menores refugiados, desde el enfoque basado en los derechos humanos, tal y como anuncia el autor desde el comienzo.

Declara a continuación que su «objetivo es conocer las principales barreras a las que se enfrenta el alumnado refugiado y solicitante de asilo durante su escolarización en el país de acogida.» Añade que "también resulta especialmente interesante reflexionar sobre qué finalidad persigue la educación de estos menores.»

Para ello revisa la literatura referida a las obligaciones de los Estados y los agentes educativos para, finalmente, proponer programas de intervención basados en las dificultades de esos escolares.

Tras un aporte considerable sobre la legislación internacional y otras, sobre las responsabilidades de los intervinientes en la educación de refugiados en todos los ámbitos y un repaso a los problemas, la conclusión no es halagüeña: «el derecho a la educación de los menores refugiados y solicitantes de asilo está siendo vulnerado por un número considerable de agentes», empezando por los Estados.

La conclusión general del monográfico es desoladora: no solo no hemos construido un mundo mejor, sino que lo hemos empeorado terriblemente. Hace más de 50 años el escritor suizo Max Frisch sentenció: «Queríamos trabajadores, pero vinieron personas» ¿Qué hubiera escrito hoy de estar vivo? Quizás: queríamos más y más riqueza, pero hemos violentado y empobrecido a la mayoría. 